\title{
Engineering Education for Sustainable Cities in AFrica: A CASE FOR RWANDA
}

\author{
Antoine Despres-Bedward \\ University of Toronto \\ Antoine.Despres.Bedward@mail.utoronto.ca
}

\begin{abstract}
Rwanda's rates of urban growth and urbanization are unprecedented [1]. This change in the number of urban-dwellers will require increased engineering talent and resources to support resulting demands on the urban infrastructure. This study builds on the engineering education literature in Rwanda, explores how the country is prepared to manage current and future urban growth rates through engineering education, and examines the processes universities undergo when reforming their engineering curriculum in Rwanda. A research team travelled to Rwanda in July, 2016 to study engineering programs and interview two faculty members at two universities. Four significant subjects emerged from this study: the involvement of the political institutions in the curriculum design and approval processes, the need for allocating new resources to meet an increase in student enrolment, the importance of considering the historical and regional contexts in the curriculum, and the need for more hands-on training in engineering education. Further study is recommended on the political involvement in engineering curriculum reform, the government-led student and faculty funding initiatives, the impacts of the historical and regional contexts on the tertiary education system, and the increase in support to practical, hands-on learning.
\end{abstract}

Keywords: Engineering Education, Curriculum Reform, Online Education, Infrastructure Development, Currere

\section{INTRODUCTION}

Rwanda has not attracted much attention from scholars studying cities and urbanization. Under $20 \%$ of its population lives in urban regions. However, in the last two decades under the Rwanda Patriotic Front (RPF) led government, the rate of change in urbanization has been termed "nothing short of extraordinary" [1, p. 331]. The change in urban growth (number of urban-dwellers) and in urbanization (percentage of population living in cities and towns) has significantly shifted. Since 1990, the number of
Rwandans living in urban centers has quadrupled. Rwanda has experienced faster urbanization than any other country in the world, with the biggest shift occurring in the RPF era $[1,3]$.

In order to design, build and maintain the new city infrastructure required for such urbanization, there is a substantial need for additional engineering talent and resources [4]. A large component of this capacity building can be achieved through the education of new Rwandan engineers who will use sustainable approaches to build and maintain new infrastructure [6, 7]. Researchers from the University of Toronto recently met with faculty members in engineering at two public universities in Rwanda. Their visit was part of a larger project aimed at exploring engineering education for sustainable cities in Africa. The objectives of this study were to build on the engineering education literature in Rwanda, explore how the country is prepared to manage current and future urban growth rates through engineering education, and examine the processes universities follow when reforming their engineering curriculum.

The method of currere [2] was used to compare my experiences as an education researcher to engineering curriculum in Rwanda. The method of currere facilitated my study of curriculum through the four phases of regression, progression, analysis and synthesis [2]. This method also allowed me to analyze my own experiences in relation to the cultural, historical and political contexts of engineering education in Rwanda.

Overarching questions were used to guide the interview conversations. These questions were influenced by prior interviews I conducted in Kenya on a similar topic. The research questions were:

1. How are institutions currently equipped to support engineering education in Rwanda?

2. What factors need to be considered to reform the engineering curricula to support rapid urban growth in Rwanda?

3. Who needs to be included in the conversation of engineering curriculum reform in Rwanda? 
4. What lessons can we learn from conversations with universities in Rwanda?

Rwanda, a former colony of Belgium, experienced a horrific genocide in 1994. Post-genocide, the country has experienced positive economic growth, low levels of corruption and secure conditions for foreign investments [3]. Because of these factors, the country is viewed as politically stable by many. Since the late 1990s, the country has rededicated resources to the development of its educational infrastructure [7] and views higher education as a key development priority [8]. Kigali, the capital of Rwanda and a rapid urbanizing center, has several post-secondary institutions which offer engineering programs. These programs attract students looking to pursue careers in infrastructure development.

The nation is poised for growth in its educational capability. Since the mid-90s, it has spent a larger proportion of its budget on higher education than any other country in the region. In addition to investing substantially in higher education, the country has also reformed several policies to create better student bursary programs facilitating student access to higher education [9]. This dedication to providing many students with opportunities to learn demonstrates the Government of Rwanda's (GoR) commitment to transforming the country in to a middle-income society by the year 2020 [3]. The GoR understands the key role that education will play in improving the social and economic wellbeing of its people. It also recognizes that university programs should be orientated towards sustainable development, including urbanization [10]. However, the quality of the graduates from Rwanda's higher education institutions has been under critique lately. Many of the graduates from these universities do not meet the needs of the industry [7]. Companies view the students as inadequate for the roles and responsibilities they were hired for; a study showed that $40 \%$ of graduates were employed in occupations they were not properly equipped for. This statistic points to the necessity of improving the quality of higher education [7].

Few studies surrounding Rwandan tertiary engineering education have been conducted. The lack of research and rapid increase in urbanization signals a need for more research of engineering education in the country. This article will build on the literature by studying the context, the content and the parties involved in the conversations of engineering education in Rwanda.

\section{METHODS}

This study of engineering education in Rwanda used data collected from a larger project for the development of engineering education for sustainable cities in Africa. The project collected data from a variety of educational and cultural contexts that included engineering education at universities in Africa. Interview data relevant to the Rwandan context were selected from the larger project.

\subsection{Participants}

Two faculty members - one from a private university and one from a public university - were interviewed for this study. For each case, participants underwent a formal consent process prior to their involvement. This process followed the ethics procedures of the University of Toronto. The identities of the participants have been anonymized using P1 for Participant 1 and P2 for Participant 2. The identities of their universities were also anonymized using Rwandan University 1 (RU1) and Rwandan University 2 (RU2).

\subsection{Data Collection}

Semi-structured interviews were conducted, recorded, and transcribed. Interviews lasted 30 to 45 minutes. Interview questions were structured around seven themes: cities and urbanization, engineering education, online and distance learning, scalability, sustainability, virtual labs, and engineering employment. Interviews were used to explore contemporary engineering education contexts in Rwanda, survey engineering education approaches including online learning strategies and methods, and integrate knowledge gained to devise highly scalable engineering education approaches suitable to resourceconstrained settings. Field notes were also taken as part of the data collection.

\subsection{Data Analysis}

Using the currere method [11], the content, context and parties involved in the conversations of curriculum were extracted from the interview transcripts. An inductive approach to extracting relevant information was then used to avoid biasing the results [12]. Meaning emerged from the phrases that revealed details related to engineering education in a Rwandan context. The details were compared across locations and participant roles. The assemblage of the two data sources provided a deeper understanding of engineering education in Rwandan universities.

\section{FINDINGS}

When reading and analyzing the interview data and the field notes, several topics emerged with both 
participants. These topics included the involvement of the government in engineering curricula, resource requirements, whether it be human, physical or financial, and the need for curriculum to reflect the right context and incorporate the proper content.

\subsection{Political Involvement}

Differing from a similar study I conducted previously in Kenya, the interviews brought forth the involvement of the federal government on several occasions. In one case, P1 mentioned:

“...all our programs are approved by we call it HEC (Higher Education Council of Rwanda). If there are any changes in the program title, we are to get the permission from them. It will also be passing through the cabinet..."

This response highlighted the importance of implicating the government in changes to the curricula. P1 provided detail of RU1 and the GoR's process of reforming a program:

"If you wanted to change the program completely ... then you are to write all the program description, module descriptions and submit it to the university. Then the university will submit to the Ministry of Education. [The] Ministry of Education [will] submit it to the cabinet for approval. Then it will go to the Higher Education Council for auditing."

This response emphasizes that the government is a key stakeholder in the engineering curriculum, and any changes will need to be aligned with its objectives. Drawing on my experience in the public sector in Canada, hearing that the federal cabinet is implicated in curriculum reform in such detail was surprising. During the interview with $\mathrm{P} 2$, and when discussing where engineering graduates end up after university, P2 also added that the government is heavily involved with infrastructure development, and stated "... [The Government of] Rwanda is very aspirational." P2's description of Rwanda underlines the Government of Rwanda's desire to improve their infrastructure development. This statement aligned with the literature's mentioning of the government's objectives and perceived behaviour. P1 added to P2's response about Rwanda's aspirations when they stated "... [RU1] was the institute [and] dream project of our president." This statement continued the idea from the literature and P2 that the government is heavily involved in infrastructure development, and thus heavily implicates itself in the engineering curriculum at the tertiary level.

\subsection{Resourcing Considerations}

The topic of resourcing for the design and delivery of engineering education was prevalent throughout the interviews with both participants. Tying in with the political conversations, I observed and analyzed multiple segments of the interviews where the participants told us about the need for more resources, whether it be human, financial or physical, to deliver to larger numbers of students. In the political conversations, the infrastructure development agenda was heavily influenced by the government. It may also be influencing the direction of students as P1 mentioned " $50 \%$ of student applications are for civil engineering ... there is a lot of development happening." P1 expressed that "[the engineering faculty at RU1] needs to recruit more staff to meet the increase in students." There exists a necessity to increase the institution's capacity to deliver to a larger number of engineers in order to meet industry needs, and to realize the aspirations of the GoR.

The organizational structure at RU2 required government funding to support it. P2 identified that "[RU2 doesn't] have enough financial aid or support to be able to give a free ride to all the students." The university is built on a cost model where the government pays for the cost of operating. However, the costs of delivering their curricula do not depend solely on the number of students and can be difficult to meet; "[t]he engineering [equipment] cost is a lot..."(P2) In my experience, online learning has been a popular topic of discussion when seeking to meet the needs of increasing student enrolment. When the suggestion of online learning as a method to increase content delivery was brought up, P2 interjected by stating:

"[t]hat's the problem is that people always talk about online as if somehow it's a cheaper way to do something that is costing us so much money right now, but my experience with online is that to do it well you know you still have to have a lot of infrastructure and human involvement to make it valuable."

This candid response echoes my experiences as an instructional designer in online course delivery, and also demonstrates a less common view on the subject.

When discussing the changing environment of faculty in engineering education, the discipline of engineering education requires human capital. P1 added that "[g]etting the professors is also very difficult..." and that "... we are facing problem in our human capacity, human resources and still now that the universities are giving pressure on staff to go for PhDs." P1's responses begin to uncover deeper meaning of the consequences of modernizing and expanding their 
workforce. As RU1 expands its reach and moves closer to modernity, the contemporary characteristics of the universities in the West follow: the university requires that new faculty have a higher level of education experience in research which may or may not be needed for teaching a higher number of students. There is a high number of professors with PhDs at the University of Toronto, but the university does provide the opportunity for the administration to hire teaching-stream employees without doctorates.

\subsection{Curriculum Context}

Throughout the interviews, the content of the curriculum and the context in which it is delivered was frequently discussed. Topics of conversation often overlapped and touched across different categories. The historical context of education in the country was mentioned by $\mathrm{P} 2$ as representing a big shift in the education system.

"Rwanda's education is struggling quite frankly. I mean it's trying to get built up. The country is only 22 years old as you know..."

Providing insight to some of the effects of the genocide on the education system, this statement echoed parts of the literature [7] and provided insight to the context of the difficulties the students have gone through. The challenges experienced by students increased when "...the education system [switched] to English seven years ago or eight years ago." (P2). P2 emphasized the switch by iterating " $[\mathrm{t}]$ hat's a huge thing to suddenly say oh you don't teach in French anymore you teach in English." As an individual who grew up schooled in both English and French in Canada, I can certainly relate to the struggle of learning subjects in both languages, especially if one was introduced much later. The challenges rebuilding from the genocide and the decision to switch from French to English schooling present circumstances to be considered when looking at the engineering curriculum in Rwanda.

In addition to discussing the historical context of education, participants shared ideas around the need to contextualize the content. The fast rate of change of industry needs is having an impact on the curriculum. P1 touched upon this when they explained:

“... things are changing very fast ... take the construction sector or irrigation sector, they are changing [them] a lot. So, you have to train our students in that. We don't want to train them five years before how civil engineering was so we are improving it."
The ideas expressed highlight how P1 recognizes that their content needs to change quicker to keep up with the pace. Online learning was addressed as a possibility to meet the changing education demands. P2 provided their views on the matter of online learning:

"It's of questionable value, quite frankly, in the United States, but when you start doing it across cultures, I'm telling you, this is interesting. With our students... there are a staggering number of sports idioms used in the sports literature. You know the students are reading along ... this technology was a home run. What does that mean to one of my students? ...the fact that so much of technology is dominated by a particular culture means that the accessibility to [the content], especially when you're talking about just delivering something online ... requires very, very strong pedagogy and educational structure..."

Contextualizing content for the development of infrastructure, a requirement pronounced by $\mathrm{P} 2$, was a key pillar of the overarching research project in Africa. P2's comments on the current state of online learning demonstrate the need for context consideration when offering distance learning across cultures. Many engineering students seek further education at universities outside of the country. P2 disagreed with the travelling aboard approach for students who wish to work in the region. P2 explained that "... what happens in graduate school, ... you create your network for life." Revealing that there is room for online learning if it can create an opportunity for students to improve their education while remaining in the region where they develop their networks and pursue their careers. P2 reiterated this by saying "...I think doing the education in Africa for Africans is absolutely what you want to see happen." This statement highlights a view point where the curriculum is a lived experience [2] and should be consumed in the location where it will be applied. P1 provided a glimpse into the current integration of technology and online learning at RU1 when mentioning that " $70 \%$ of [their] staff members [are] using [their learning platform]" for the distribution of notes, assignments and other learning activities. Based on the responses and observations at both RU1 and RU2, I can see that online learning needs more consideration for context, but that incremental integration of online components has already started to enter the curriculum.

\subsection{The Need for Hands-On Training}

The need for practical and hands-on training filled a large portion of the conversation with both
CEEA17; Paper 024

University of Toronto; June 4-7, 2017 
participants. There was resistance expressed towards adopting a primarily online pedagogical approach because of the need for hands-on training in engineering education. P1 shared their thoughts about online engineering courses by saying “...we don't offer online because [engineering education at RU1] needs some hands-on training." P2 added their perspective to the topic when stating:

"...engineering education really is in dire need of much more hands-on practice. What they always say is that we study theory in the university and that's a code word for we don't actually really do anything... there's a huge need for getting [hands-on practice in] engineering education."

P2 furthered their sentiment when asserting:

"...there's a massive problem to get the entire education system so that it starts ... rising in quality and [includes] more critical thinking, more hands on, more problem solving, all the things you would like engineers to be able to do."

Responses to the questions about the future of engineering education at both RU1 and RU2 demonstrated the inclusion of hands-on training as an important requirement of the curriculum. This need impacted RU2 in the development of its programs. P2 shared:

"...both of [our] degree [programs] are designed ... [with] what the university calls professional degrees ... they are primarily intended for people who are going to go in to practice after their master's degrees. They are not preparation for $\mathrm{PhD}$ [degrees]. They are not research oriented. They are practical oriented towards practice and practical education."

These strong responses to the requirements of engineering education by both participants provide valid arguments for the necessity for more hands-on training as a key proponent in the reform of engineering curriculum.

\section{CONCLUSION}

The rapid and large-scale urbanization will create considerable challenges and opportunities for engineers and engineering education. Using the method of currere, this study focused on the context, the content and the parties involved in the conversations of engineering education in Rwanda.
Four significant subjects emerged from this study. These subjects were:

1. the involvement of the political institutions in the curriculum design and approval processes;

2. the need for allocating new resources to meet an increase in student enrolment;

3. the importance of considering the historical and regional contexts in the curriculum; and,

4. the need for more hands-on training in engineering education.

There exists a real desire in Rwanda from its government to support urbanization and increase socioeconomic wellbeing in the country through education reform. Political involvement in engineering curriculum, limited resources, including human, technological and financial resources, a unique historical and regional context, and the need for more hands-on training all present challenges for the future of the engineering programs.

The findings from this study may be used to provide insight in to curriculum studies at tertiary institutions in Rwanda. Further study is needed surrounding political involvement in engineering curriculum reform, government-led student and faculty funding and resourcing initiatives, the impacts of the historical and regional contexts on the tertiary education system, and the increase in support of practical, hands-on learning.

\section{ACKNOWLEDGEMENTS}

I would like to thank my research team for their continued support, and I would like to thank Kirstin Newfield and Nadine Ibrahim for travelling to Rwanda with me to pursue our research passions.

\section{REFERENCES}

[1] Tom Goodfellow, "Rwanda's Political Settlement and the Urban Transition: Expropriation, Construction and Taxation in Kigali," Journal of Eastern African Studies, vol. 8, no. 2, pp. 311-329, 2014.

[2] William F. Pinar, "The Method of Currere," Annual Meeting of the American Research Association, Washington, D.C., 1975.

[3] Niamh Gaynor, “A Nation in a Hurry': The Costs of Local Governance Reforms in Rwanda," Review of African Political Economy, vol. 41, no. S1, pp. S49-S63, 2014.

[4] Nadine Ibrahim, Murray Metcalfe, Rahim Rezaie, Daniel Hoornweg,... Antoine Despres-Bedward, "Engineering Education for Sustainable Cities in Africa," in Proc. Engineering Education for Sustainable Development Conf., EESD8, (Bruges, Belgium; 4-7 September 2016), 2016. 
[5] Tomasz Arciszewski, "Future of Engineering Education," Management, Procurement and Law, vol. 167, no. MP1, pp. 46-59, 2014.

[6] Tharindu Liyanagunawardena, Shirley Williams, and Andrew Adams, "The Impact and Reach of MOOCs: A Developing Countries' Perspective," eLearning Papers, no. 33, pp.1-8, 2013.

[7] Faustin Mutwarasibo, Pierre Canisius Ruteranaa, and Ingrid Andersson, "Boundary Crossing Between Higher Education and the World of Work: A Case Study in Post-1994 Rwanda," Higher Education Research \& Development, vol. 33, no. 5, pp. 962-977, 2014.

[8] Moses Oketch, Trist McCowan, and Rebecca Schendel, "The Impact of Tertiary Education on Development: A Rigorous Literature Review," Department for International Development, 2014.
[9] Rebecca Schendel, "Constructing Departmental Culture to Support Student Development: Evidence from a Case Study in Rwanda," Higher Education, vol. 72, pp. 487504, 2016.

[10] Telesphore Kabera, "Environmental impact assessment in higher education institutions in East Africa: The Case of Rwanda," Environmental Science and Pollution Research, vol. 24, no. 8, pp. 7852-7864, 2017.

[11] William F. Pinar, "What is Curriculum Theory?," New York, NY: Routledge Taylor \& Francis Group 2012, 2nd Edition.

[12] Virginia Braun, and Victoria Clarke, "Using thematic analysis in psychology," Qualitative Research in Psychology, vol. 3, no. 2. pp. 77-101, 2006. 